\title{
PREDICTION OF DRAPE COEFFICIENT BY ARTIFICIAL NEURAL NETWORK
}

\author{
Adel Ghith ${ }^{1,2 *}$, Thouraya Hamdi ${ }^{1,3}$, Faten Fayala ${ }^{1,3}$ \\ ${ }^{1}$ University of Monastir, National Engineering School, Textile Department, Ibn El Jazzar Street, 5019 Monastir, Tunisia \\ ${ }^{2}$ ATSI: Research unit of automatic, Signal and Image analysis, University of Monastir, Ibn El Jazzar Street, 5019 Monastir, Tunisia \\ ${ }^{3}$ LESTE, Laboratory of Energetic and Thermic systems, University of Monastir, Ibn El Jazzar Street, 5019 Monastir, Tunisia \\ ${ }^{*}$ Corresponding author: adel.ghith@gmail.com
}

\begin{abstract}
:
An artificial neural network (ANN) model was developed to predict the drape coefficient (DC). Hanging weight, Sample diameter and the bending rigidities in warp, weft and skew directions are selected as inputs of the ANN model. The ANN developed is a multilayer perceptron using a back-propagation algorithm with one hidden layer. The drape coefficient is measured by a Cusick drape meter. Bending rigidities in different directions were calculated according to the Cantilever method. The DC obtained results show a good correlation between the experimental and the estimated ANN values. The results prove a significant relationship between the ANN inputs and the drape coefficient. The algorithm developed can easily predict the drape coefficient of fabrics at different diameters.
\end{abstract}

\section{Keywords:}

Bending rigidity, drape coefficient, neural networks, back-propagation

\section{Introduction}

Drape is the term used to describe the way a fabric hangs down under its own proper weight in folds. It gives an idea on how good a garment looks in use. Moreover, drape indicates the conformity of garments to body contours. When a fabric is draped, various configurations are found and different forms are obtained.

The study of the textile fabrics 'drapability' is related to the deformation capacities and thus their harmonised aptitude with the bodies in contact. When selecting fabrics for garments, several problems due to nonconformity between the style of the draped model are found. So, drape is a significant textile property which must be taken into account for garment selection.

Drape has been widely studied in the literature review. The fabric drape has been measured by the F.R.L. Drapemeter according to Chu et al. [5]. They defined a dimensionless value called the drape coefficient (DC). Their work was revised by Cusick [10] who modified the experimental method and used a parallel light source reflecting a circular specimen drape shadow from a hanging disc onto a paper ring. The drape coefficient calculation is based at this stage in terms of paper tracing and weighing method. It is defined as the ratio between the draped shadow paper weight and the full specimen paper weight. The drape coefficient varies from 0 to 1 . It is high on stiff fabrics and low on floppy fabrics. But, the hanging area of the samples modifies significantly the value of the drape coefficient (DC).

Collier et al. [7] presented a digital drape meter to evaluate drape coefficient. The method is based on the photovoltaic cells light absorbance, placed in the bottom surface of the Cusick drape meter, to determine the amount of light blocked by a fabric specimen draped on a platform. In fact, the absorbed light amount by the photovoltaic cells is in accordance with the drape amount. So, the drape coefficient is calculated and displayed digitally.

In recent years, the drape coefficient determination is based on numerical considerations given by scanned images obtained from a camera mounted on Cusick drapemeter [1,6,9,11-13].

The drape is a complex deformation, closely related to the fabrics bending properties.

The bending of woven fabrics has been widely investigated in the literature. Actually, Abbott et al. [1], Jeong [18] and Hu et al. [16] analysed the bending behaviour of plain-weave fabrics. It has been proved that the bending rigidity and bending hysteresis are high correlated. Pierce [23] developed a relationship to calculate the stiffness of a fabric in any direction in terms of stiffness in the warp and weft directions. Cooper [8] used Cantilever methods to study the stiffness of fabrics in various directions. Jedda $\mathrm{H}$. et al. [17] proposed an artificial neural network (ANN) to predict the fabric drape using FAST parameters. Behre [3], Grosberg [14], Lindbergh et al. [19] and Oloffson [22] found that the most significant parameters which are correlated well with drape are the bending length and the bending rigidity.

Other Authors had developed ANN techniques to evaluate drape coefficient. We can cite Antony Lam et al. [2], they used a multilayer neural network with a back propagation (BP) technique and a Radial Basis Function (RBF) to predict the drape coefficient. In their paper, they consider as input 
parameters: the fabric weight, the fabric thickness, the bending rigidity, the shear rigidity, the hysteresis of shear force at 0.5 degrees, the linearity of load-extension curve and the weave structure. The BP method was more effective than the RBF method but they found that the RBF method was faster when it came to training.

In this paper we present an ANN approach to predict the drape coefficient. The proposed model estimates the drape coefficient as function of bending rigidities, fabric specimen diameter and hanging weight. The originality of this approach is to consider a very limited input data which are obtained easily with basic equipment. There is no need to carry out complex tests as shear apparatus or to use specific and expensive machines to identify input characteristics presented in like other works.

To develop the ANN model, several configurations were evaluated. An optimal neural network was selected with one hidden layer and four hidden neurons. The ANN was trained with a training data set and tested with another untrained data set. The drape coefficient values obtained from the ANN were compared to experimental data obtained from Cusick drape meter.

\section{Materials and methods}

Fifty one samples, made up of two kinds of weave (plain and twill), were tested for this study. We began by calculating the drape coefficient using the cut and weight method with a Cusick Drape meter according to ISO 9073-9. This method consists on the preparation of circular fabric samples which are draped over a horizontal circular disk with a constant and fixed diameter $(18 \mathrm{~cm})$. The samples, which have bigger diameters than the circular disk, fold under their proper weights. After fifteen minutes of stabilisation we draw the shadows of the draped samples projected on a paper and finally we cut and weigh the obtained forms of paper. The sample diameters used in this study are 24,30 and $36 \mathrm{~cm}$.

To calculate the drape coefficient we use equation 1 .

$$
D C=\frac{\text { paper shaded area mass }(g)}{\text { paper total mass }(g)}
$$

For each sample, we calculate the drape coefficient (DC) for the three diameters. The variation of the $\mathrm{DC}$ values is presented in Table1.

We note that higher the sample diameter, lower is the drape coefficient. When the sample area increases, the hanging mass is more important and the mean diameter of the drape shadow is smaller.

Figure 2 presents the variation of the drape coefficient (DC) with samples diameters.

For each sample, we note that the drape coefficient varies with the hanging diameter. There is a strong relationship between the drape coefficient and the diameter of the used specimen. We note also that when the used diameter is higher the value of the drape coefficient decreases.

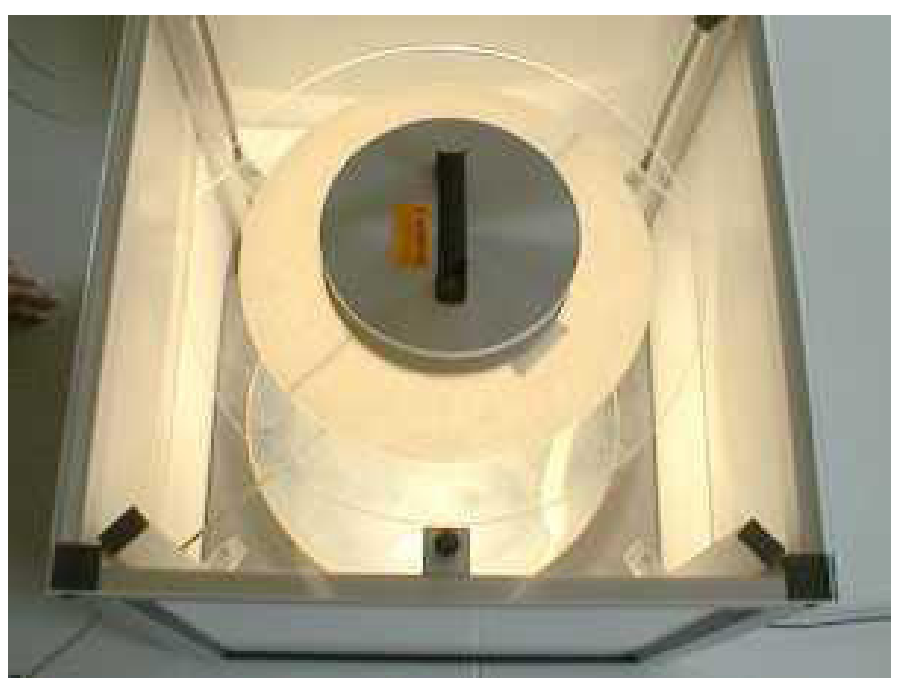

Figure 1. The Cusick Drape meter

Table 1. The range of the DC parameter

\begin{tabular}{|c|c|c|c|}
\hline \multirow{2}{*}{} & \multicolumn{3}{|c|}{ Sample Diameters } \\
\cline { 2 - 4 } & $\mathbf{2 4} \mathbf{~ c m}$ & $\mathbf{3 0} \mathbf{~ c m}$ & $\mathbf{3 6}$ \\
\hline Min & 0,62 & 0,28 & 0,2 \\
\hline Max & 0,98 & 0,87 & 0,6 \\
\hline Mean & 0,868 & 0,55 & 0,348 \\
\hline Standard deviation & 0,05946988 & 0,13271021 & 0,09193519 \\
\hline
\end{tabular}


The area of the hanging disc is constant; the increase of the diameter of fabric samples gives a best fallen. The hanging weight in higher diameter samples is more significant, the shade is more compact due to the gravity and the drape coefficient decreases. So, we consider that the drape is influenced by the mass of fabrics in free suspension.

Also, the variation of the drape coefficient with the sample diameter is not linear, the structure of weaving and especially the bending rigidities of samples influence strongly the drape coefficient.

\subsection{Measurement of the bending rigidities}

The bending rigidities parameters were measured using the Cantilever test according to ASTM D1388. The cantilever test is an apparatus developed by Pierce [23] and performed later. The test consists on allowing a rectangular strip of fabric to bend under its proper weight to a fixed angle equal to $41,5^{\circ}$. It permits the measure of fabric bending rigidities in weft, warp and in any direction [15]. When the tip of the strip reaches the inclined plan, the overhanging length is measured and noted

$\mathrm{L}$. The bending rigidity is calculated according to the following equation:

$B_{(\mu N . m)}=W_{\left(\frac{g}{m^{2}}\right)} \times(L / 2)^{3}{ }_{\left(\mathrm{cm}^{3}\right)} \times 10^{-2}$

(2) Where $X_{i}$ is the input parameters vector of dimension $M, Y$ the

Where: $L$ is the overhanging length, $W$ the fabric surface mass, $\mathrm{B}$ the bending rigidity.

\subsection{Measurement of the hanging weight}

The hanging weight is calculated by the following equation:

$M_{(g)}=W_{\left(g / m^{2}\right)} \times\left(S_{\left(m^{2}\right)}-S_{0\left(m^{2}\right)}\right)$ output parameters vector of dimension $D, g(x)$ and $f(x)$

Where $M$ is the hanging weight, $W$ the fabric surface mass, $S$ the surface of the circular specimen of the fabric sample (diameter equal to $24,30 \& 36 \mathrm{~cm}$ ), $\mathrm{S}_{0}$ the surface of Cusick platform drape meter (diameter equal to $18 \mathrm{~cm}$ ).

In Table 2 we present the 51 samples characteristics used in this paper for the neural network model. We also present in the same table the drape coefficient of each fabric calculated at different diameters.

The first 38 samples were used for training the ANN model and the last 13 samples for the test.

\subsection{Artificial Neural Network model}

A neural network is a mathematical model inspired by biological brains [20][21]. It consists of an interconnected group of artificial neurons or nodes. Neural networks are used to model complex relationships between inputs and outputs parameters. The most widely used ANN is known as multilayer feed forward neural network. This neural approach models the relationship between input parameters $(X)$ and output parameters $(Y)$ in the form presented by equation 4 .

$$
Y=g\left[\sum_{j=a}^{M} w_{k j} f\left\{\sum_{i=0}^{D} w_{i j} X_{i}\right\}\right]
$$

the functions of activation, $\mathrm{w}_{\mathrm{kj}}$ the weights between neurons of input and hidden layer, $w_{i j}$ the weights between neurons of hidden and output layers.

Back-propagation training algorithm was used. The training was realised with both inputs and outputs. In fact, input parameters propagate through the network layer by layer producing in the end a response which was the output of the network. The output was then compared with the target response and generates

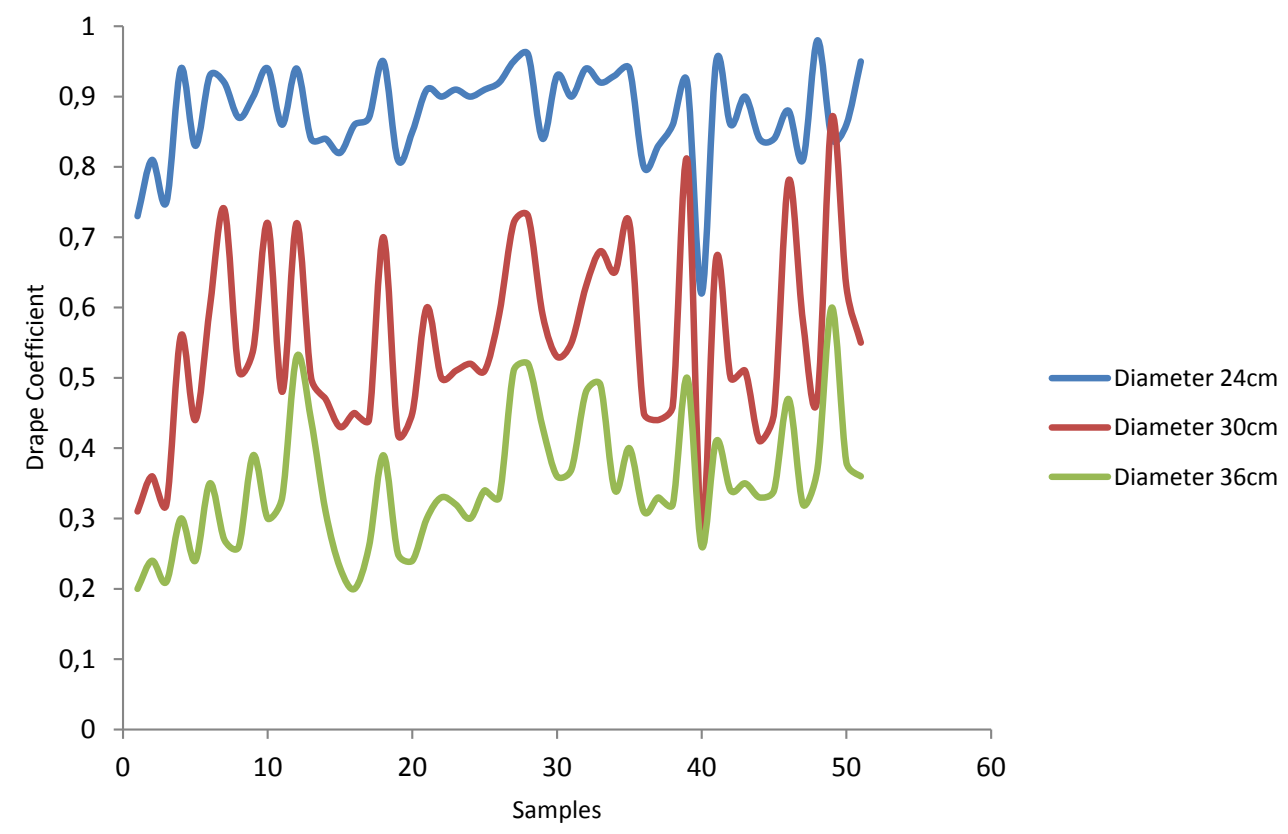

Figure 2. Drape Coefficient at different diameters 
Table 2. Structural properties of fabric samples

\begin{tabular}{|c|c|c|c|c|c|c|c|c|}
\hline \multirow{2}{*}{$\mathbf{N}$} & \multirow{2}{*}{ Fabric Id. } & \multicolumn{3}{|c|}{ Bending Rigidities } & \multirow{2}{*}{$W_{\left(g / m^{2}\right)}$} & \multicolumn{3}{|c|}{ Experimental drape coeficient } \\
\hline & & $B_{\text {skew }}$ & B warp $_{\text {w }}$ & $\mathbf{B}_{\text {weft }}$ & & $24 \mathrm{~cm}$ & $30 \mathrm{~cm}$ & $36 \mathrm{~cm}$ \\
\hline 1 & Twill 01 & 0,0806 & 0,2502 & 0,1996 & 105 & 0,73 & 0,31 & 0,2 \\
\hline 2 & Twill 02 & 0,8719 & 0,7902 & 0,9591 & 187,33 & 0,81 & 0,36 & 0,24 \\
\hline 3 & Twill 03 & 0,5919 & 0,6799 & 0,3345 & 231,2 & 0,75 & 0,32 & 0,21 \\
\hline 4 & Twill 04 & 0,6023 & 0,8173 & 0,916 & 175,6 & 0,94 & 0,56 & 0,3 \\
\hline 5 & Twill 05 & 0,7138 & 0,9009 & 0,6397 & 238,4 & 0,83 & 0,44 & 0,24 \\
\hline 6 & Twill 06 & 1,7936 & 1,3475 & 0,774 & 263,2 & 0,93 & 0,6 & 0,35 \\
\hline 7 & Twill 07 & 0,7202 & 2,0959 & 1,162 & 151,2 & 0,92 & 0,74 & 0,27 \\
\hline 8 & Twill 08 & 0,6704 & 0,7477 & 0,8136 & 218 & 0,87 & 0,51 & 0,26 \\
\hline 9 & Twill 09 & 0,4138 & 0,3778 & 0,3607 & 137,6 & 0,9 & 0,54 & 0,39 \\
\hline 10 & Twill 10 & 4,6499 & 5,0372 & 4,107 & 340 & 0,94 & 0,72 & 0,3 \\
\hline 11 & Twill 11 & 0,7456 & 1,2754 & 0,942 & 184 & 0,86 & 0,48 & 0,33 \\
\hline 12 & Twill 12 & 1,281 & 0,8758 & 6,1885 & 110,66 & 0,94 & 0,72 & 0,53 \\
\hline 13 & Twill 13 & 0,3983 & 0,5397 & 1,4345 & 175,5 & 0,84 & 0,5 & 0,44 \\
\hline 14 & Twill 14 & 1,0331 & 0,4279 & 0,996 & 184 & 0,84 & 0,47 & 0,31 \\
\hline 15 & Plain 01 & 0,6961 & 0,6961 & 1,1549 & 221,4 & 0,82 & 0,43 & 0,23 \\
\hline 16 & Plain 02 & 0,142 & 0,1861 & 0,3788 & 95,4 & 0,86 & 0,45 & 0,2 \\
\hline 17 & Plain 03 & 0,15 & 0,1901 & 0,3882 & 95,8 & 0,87 & 0,44 & 0,26 \\
\hline 18 & Plain 04 & 0,4997 & 1,1395 & 0,5034 & 97,6 & 0,95 & 0,7 & 0,39 \\
\hline 19 & Plain 05 & 0,688 & 2,1086 & 0,3787 & 258,8 & 0,81 & 0,42 & 0,25 \\
\hline 20 & Plain 06 & 0,6164 & 0,834 & 0,4866 & 214,4 & 0,85 & 0,45 & 0,24 \\
\hline 21 & Plain 07 & 0,643 & 0,978 & 0,5089 & 125,6 & 0,91 & 0,6 & 0,3 \\
\hline 22 & Plain 08 & 0,566 & 0,8543 & 0,5638 & 121,6 & 0,9 & 0,5 & 0,33 \\
\hline 23 & Plain 09 & 0,5616 & 0,8534 & 0,562 & 122,4 & 0,91 & 0,51 & 0,32 \\
\hline 24 & Plain 10 & 0,57 & 0,8624 & 0,5551 & 123 & 0,9 & 0,52 & 0,3 \\
\hline 25 & Plain 11 & 0,566 & 0,8001 & 0,5622 & 122,4 & 0,91 & 0,51 & 0,34 \\
\hline 26 & Plain 12 & 0,7371 & 2,2356 & 0,9457 & 166,6 & 0,92 & 0,59 & 0,33 \\
\hline 27 & Plain 13 & 0,6154 & 0,4049 & 1,6084 & 66,4 & 0,95 & 0,72 & 0,51 \\
\hline 28 & Plain 14 & 0,6052 & 0,412 & 1,6103 & 66,8 & 0,96 & 0,73 & 0,52 \\
\hline 29 & Plain 15 & 0,4244 & 0,4624 & 0,4822 & 129,2 & 0,84 & 0,59 & 0,43 \\
\hline 30 & Plain 16 & 1,4247 & 3,2751 & 1,7728 & 224 & 0,93 & 0,53 & 0,36 \\
\hline 31 & Plain 17 & 1,2424 & 1,1078 & 1,7689 & 242,66 & 0,9 & 0,55 & 0,37 \\
\hline 32 & Plain 18 & 1,5927 & 0,8856 & 2,2182 & 166,66 & 0,94 & 0,63 & 0,48 \\
\hline 33 & Plain 19 & 2,1056 & 6,5107 & 6,5107 & 220,33 & 0,92 & 0,68 & 0,49 \\
\hline 34 & Plain 20 & 0,9267 & 1,3422 & 0,7909 & 138,33 & 0,93 & 0,65 & 0,34 \\
\hline 35 & Plain 21 & 0,8859 & 1,5049 & 0,5594 & 130 & 0,94 & 0,72 & 0,4 \\
\hline 36 & Plain 22 & 0,2828 & 0,7634 & 0,0877 & 103 & 0,8 & 0,45 & 0,31 \\
\hline 37 & Plain 23 & 0,2885 & 0,492 & 0,2885 & 160 & 0,83 & 0,44 & 0,33 \\
\hline 38 & Plain 24 & 0,3417 & 0,5906 & 0,3417 & 140 & 0,86 & 0,46 & 0,32 \\
\hline 39 & Plain 25 & 2,8741 & 2,5821 & 0,3607 & 194 & 0,92 & 0,81 & 0,5 \\
\hline 40 & Plain 26 & 0,0983 & 0,2332 & 6,1885 & 68 & 0,62 & 0,28 & 0,26 \\
\hline 41 & Plain 27 & 1,0718 & 1,0328 & 1,4345 & 198 & 0,95 & 0,67 & 0,41 \\
\hline 42 & Plain 28 & 0,1588 & 0,0409 & 0,996 & 95,5 & 0,86 & 0,5 & 0,34 \\
\hline 43 & Plain 29 & 0,6176 & 0,3773 & 0,3784 & 110 & 0,9 & 0,51 & 0,35 \\
\hline 44 & Plain 30 & 0,1437 & 0,0901 & 0,0004 & 70 & 0,84 & 0,41 & 0,33 \\
\hline 45 & Twill 15 & 0,3716 & 0,3025 & 0,3784 & 65 & 84,4 & 0,45 & 0,34 \\
\hline 46 & Twill 16 & 4,2584 & 8,3607 & 2,4387 & 280 & 88 & 0,78 & 0,47 \\
\hline 47 & Twill 17 & 0,9483 & 0,8346 & 1,1664 & 162 & 81 & 0,58 & 0,32 \\
\hline 48 & Twill 18 & 0,2499 & 0,48601 & 0,419 & 85 & 98 & 0,47 & 0,37 \\
\hline 49 & Twill 19 & 4,7123 & 2,8645 & 2,2093 & 266 & 84 & 0,87 & 0,6 \\
\hline 50 & Twill 20 & 0,3998 & 0,2602 & 0,4555 & 130 & 86 & 0,63 & 0,38 \\
\hline 51 & Twill 21 & 0,6767 & 0,5251 & 1,3217 & 167 & 0,95 & 0,55 & 0,36 \\
\hline
\end{tabular}


error signals. These errors propagate in a backward direction through the network. In this phase, the weights of the network are adjusted to minimise the value of the quadratic error average (MSE) between the ANN response and the experimental values. The MSE calculation is given by equation 5 .

$$
M S E=1 / 2 \sum_{l}^{\mathrm{n}}\left(t_{\mathrm{i}}+y_{\mathrm{i}}\right)^{2}
$$

Where $t_{i}$ is the $i^{\text {th }}$ desired output (target), $y_{i}$ the $i^{\text {th }}$ output.

To build correctly a neural network, several parameters must be optimised such as the number of hidden layers, the number of neurons in the hidden layer, the rate of training and the numbers of iterations during the training. The general architecture of the ANN is given by Figure 3 .

\subsection{Optimisation of the ANN model}

The first decision in connection with the parameters of the neural network is to find out the number of hidden layers. The use of more than one hidden layer allows having good results. But, Chattopadhyay and Guha [4] show in their study that the increase of the hidden layers number is able to produce a considerable improvement of performances of the network if only all the other parameters of the network are optimised.

\section{Number of hidden layers}

The number of hidden layers $\left(\mathrm{N}_{\text {hidden }}\right)$ must be selected according to the correlation coefficient $(R)$ existing between the experimental and the estimated values given by the network. The number of hidden layers giving the highest value of $\mathrm{R}$ must be selected (Figure 5). In this study, best results are obtained with only one hidden layer of neurons (Figure 4).

\section{Number of hidden neurons}

The number of hidden neuron is a very significant factor in the neural networks system. In this study, we found that the value of hidden neurons equal to 4 is the best value. It gives

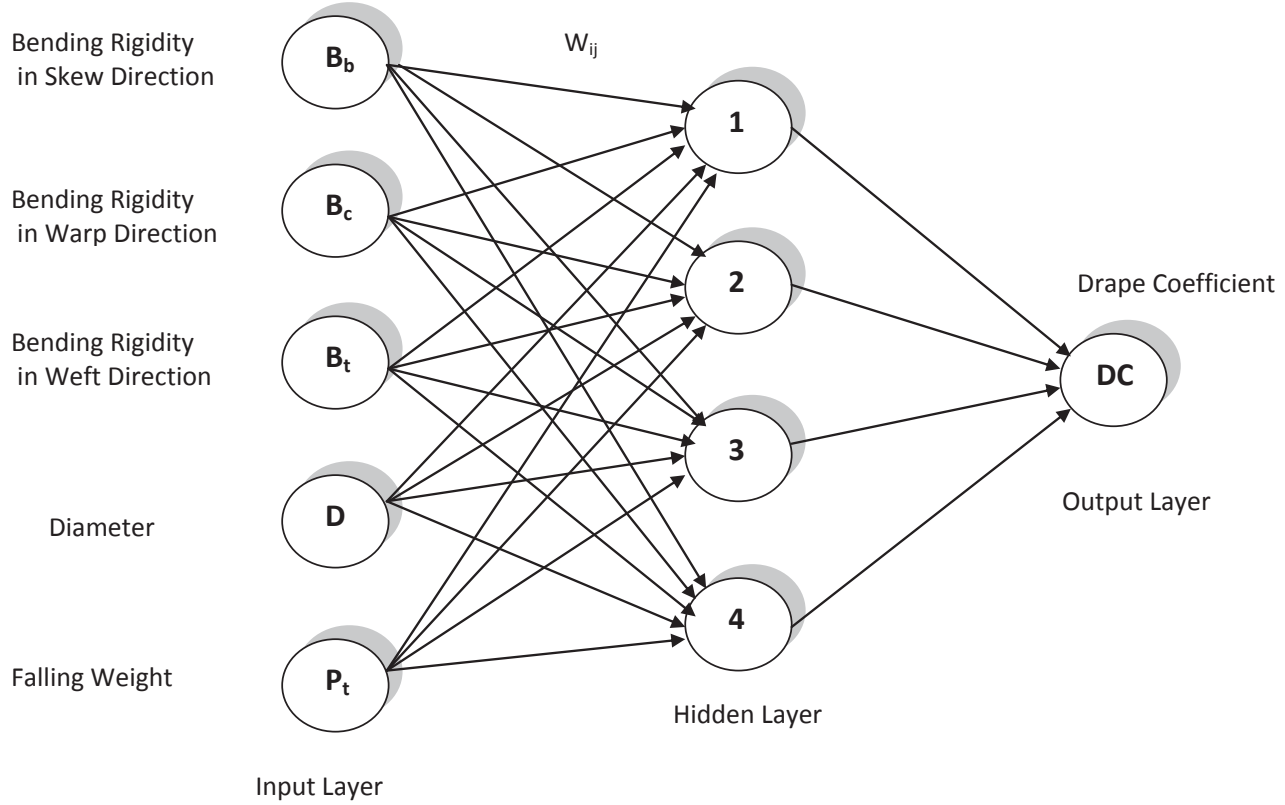

Figure 3. The Artificial Neural Network Structure

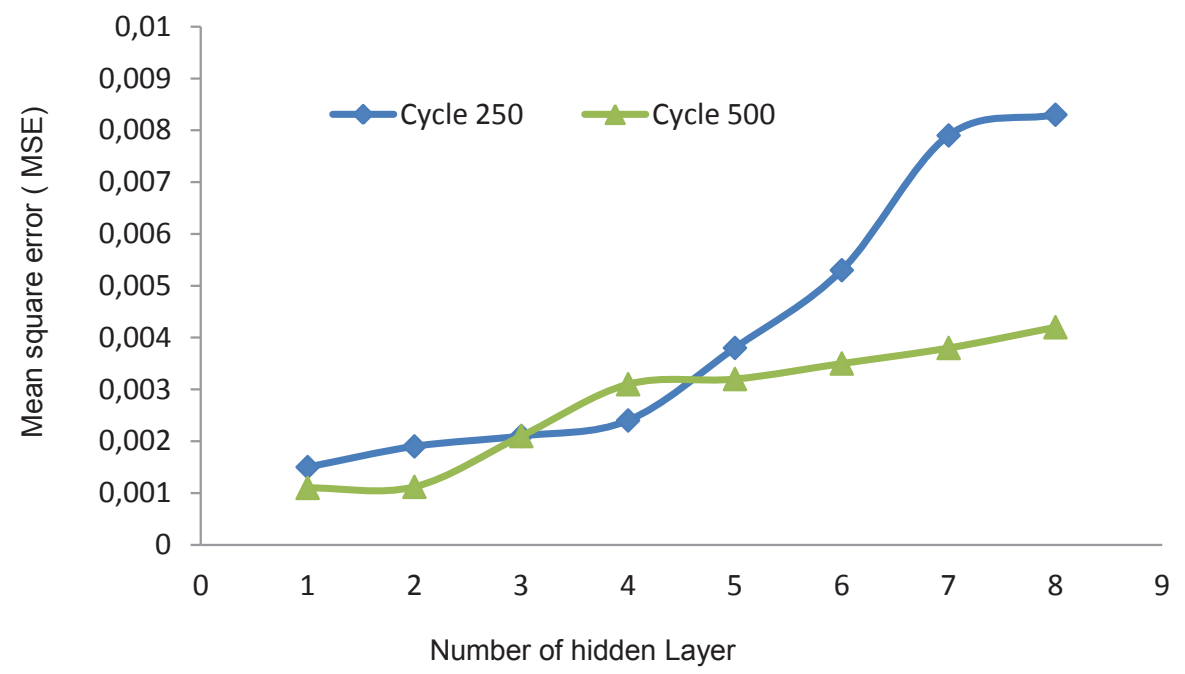

Figure 4. Effect of the number of hidden layers variation on MSE 
a minimal quadratic error (MSE) and a maximum efficiency of the model ( $\mathrm{R}$ much closer to 1 ) as presented in Figure 6 and Figure 7 .

\section{Iteration count}

The iteration count to be considered must give the smallest MSE. In this paper the cycle's number equal to 500 gives best results as presented by Figures 8 and 9 .

In Figure 5, we can note that when the iteration count increases, the correlation coefficient is higher. But an accurate analysis must be developed to determine the influence of the iteration count on the quadratic error of the ANN and on the correlation coefficient $R$. The results are presented by Figures 8 and 9 .

The iteration count 500 gives the highest correlation coefficient and the lowest MSE.

\section{Results and discussion}

The structure of the ANN was made with one hidden layer, 4 hidden neurons, 5 inputs and the drape coefficient as output. The activation function used was the sigmoid function and the iteration count was equal to 500 .

13 samples were used to test the neural network model developed. The pace of the average quadratic error obtained after 500 iterations was presented in Figure 10. It shows a good convergence of the algorithm.

We calculated the correlation coefficient of the samples and we noted that there was a good correlation between the drape coefficients measured experimentally and those calculated by the neural network's method for the used diameters (24, 30 and 36) (Figure 11). The correlation coefficient obtained (0.916) explains a good quality of the forecast given by the training algorithm.

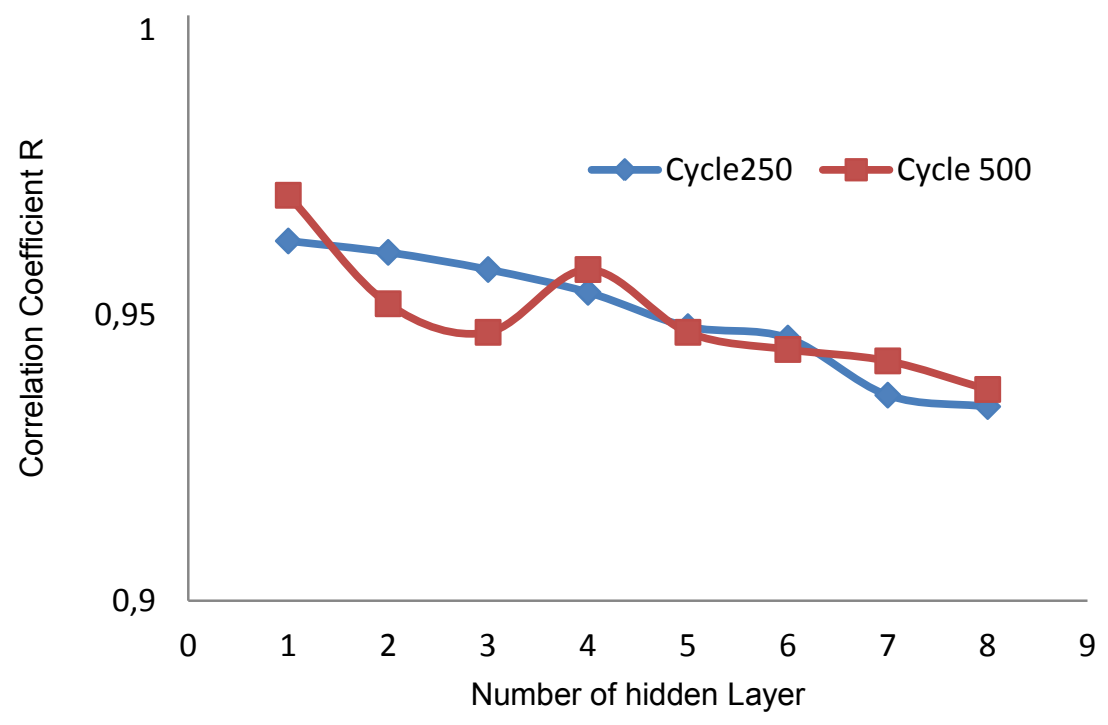

Figure 5. Effect of the number of hidden layers variation on the correlation coefficient $R$

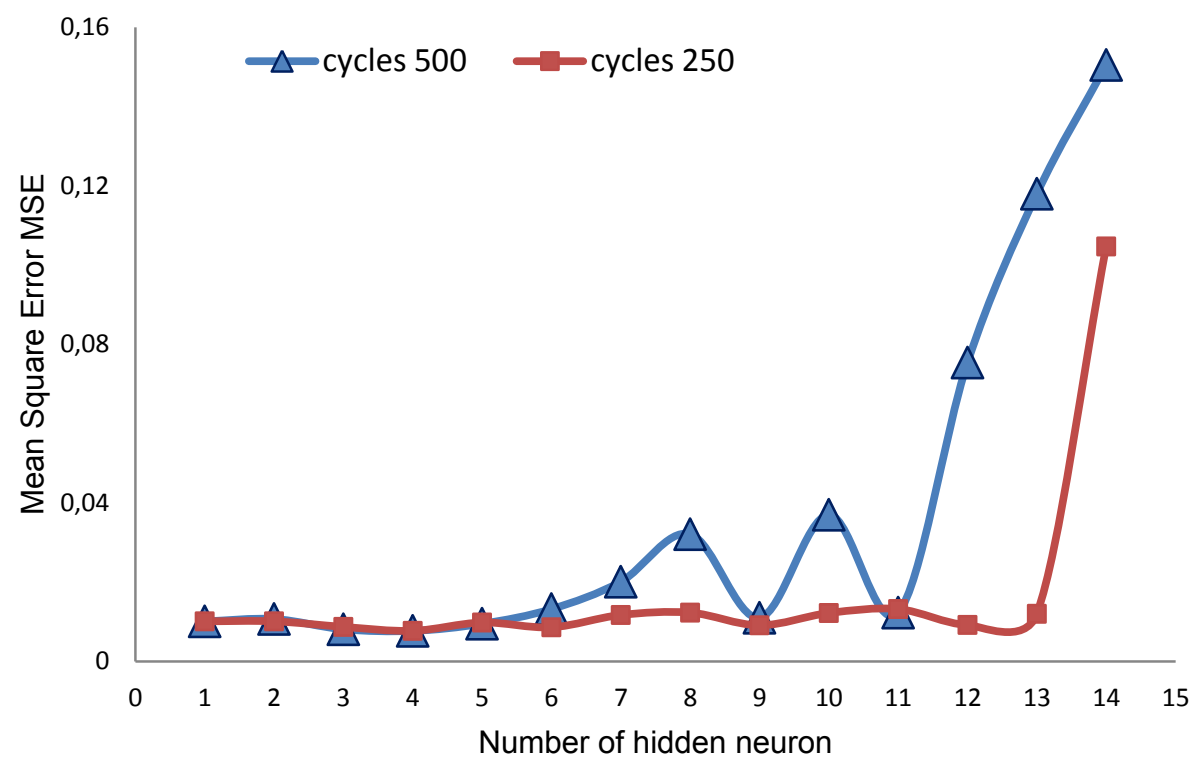

Figure 6. Effect of the number of hidden neurons variation on MSE 


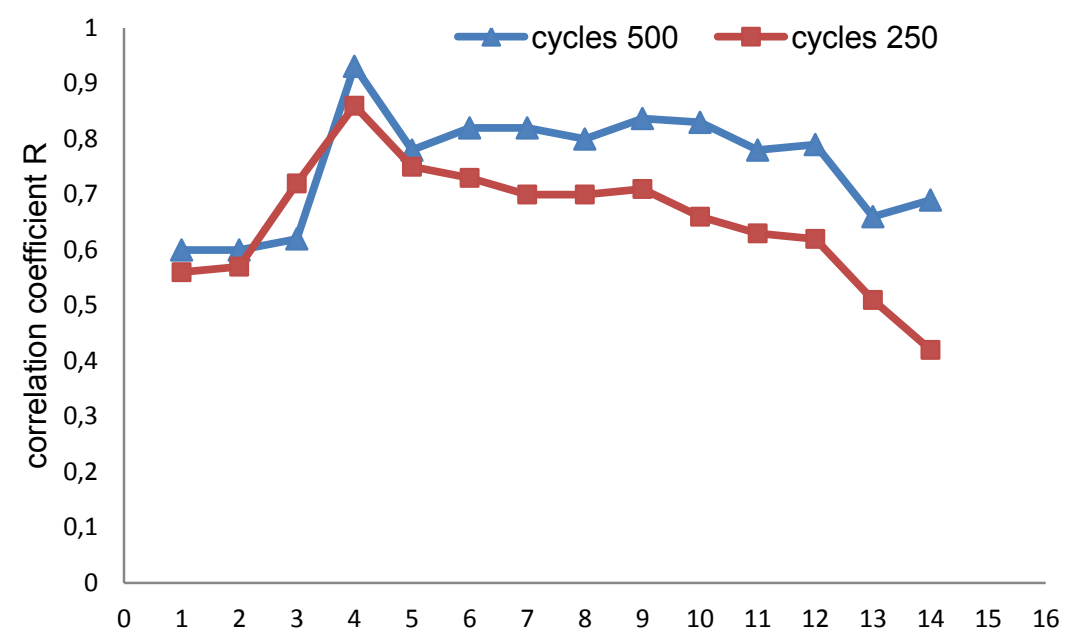

\section{Number of hidden neurons}

Figure 7. Effect of the number of hidden neurons variation on the correlation coefficient $R$

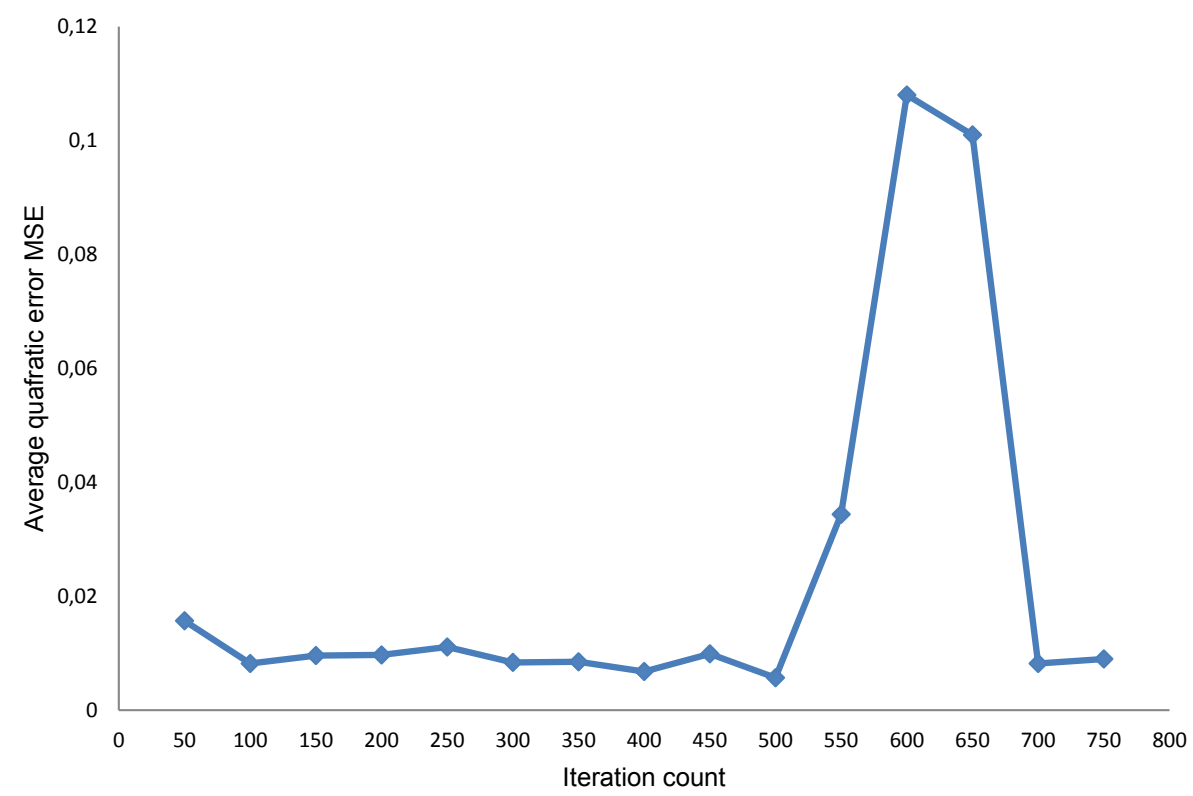

Figure 8. Effect of the iteration count variation on MSE

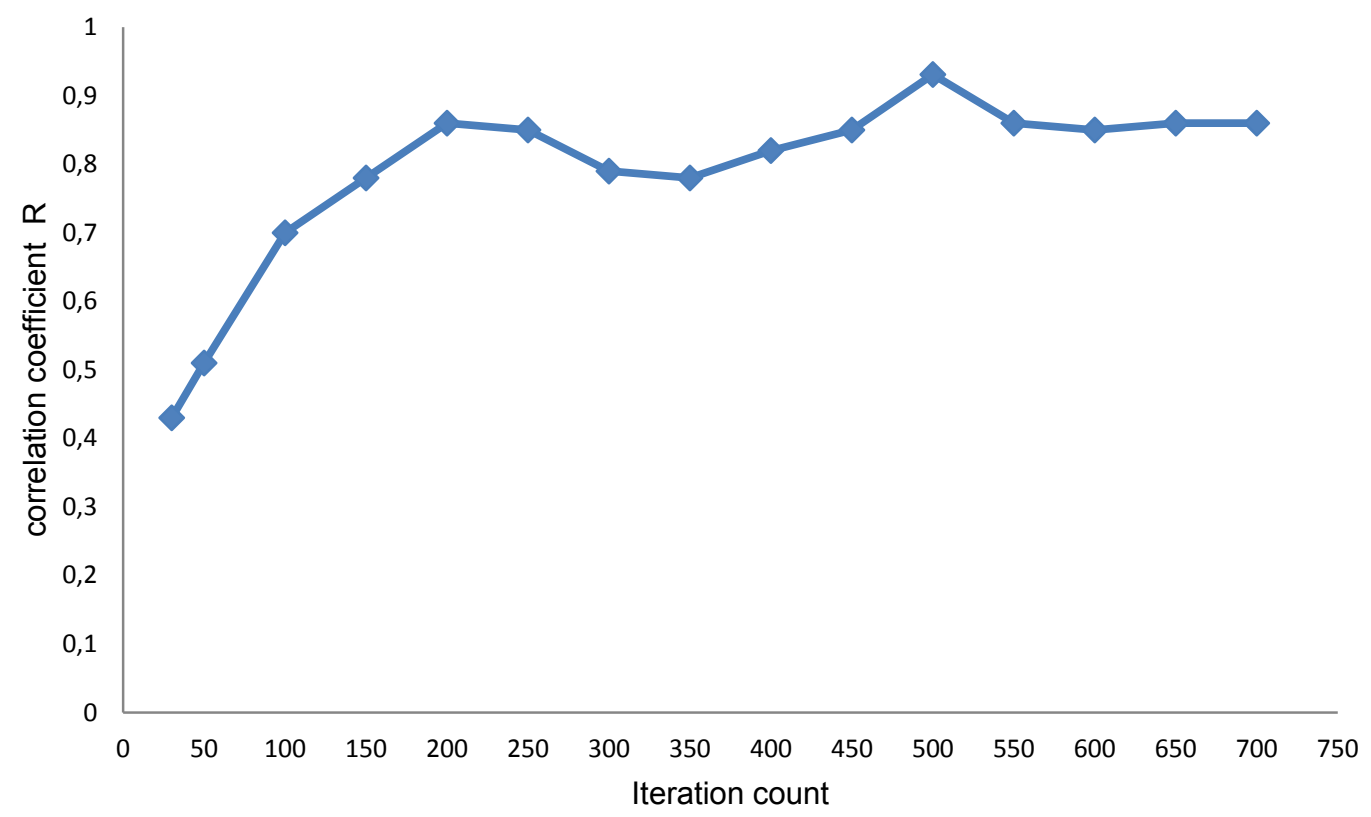

Figure 9. Effect of the iteration count variation on Correlation Coefficient $\mathrm{R}$ 


\section{CONCLUSIONS}

In this paper an ANN was developed and optimised to predict the drape coefficient for different fabric diameters. We simplified the forecast of the drape coefficient by simple, basic and fast physical testing fabric properties which give a good correlation between the experimental and the predicted values of the drape coefficient.
This method gives efficient results of the drape coefficient and can replace the cut and weight method which needs to draw the shadow of the folds of the fabric. The proposed model has been found efficient for proving correlation between the bending rigidities, the hanging weight and the drape.

The results obtained can be used to predict the drape coefficient at different diameters; they can help textile designers in the choice of the fabric structure to be used in garments.

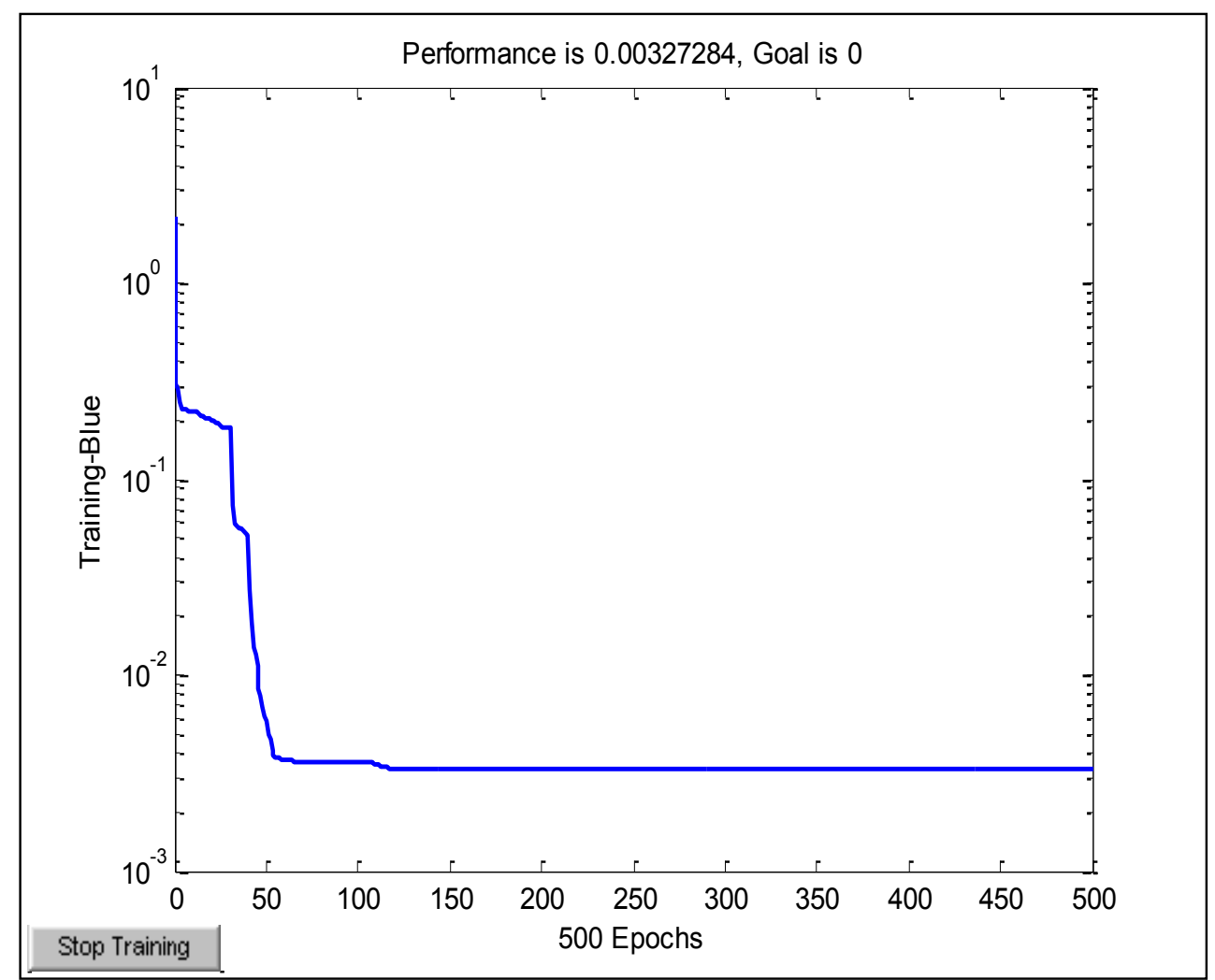

Figure 10. Curve of training

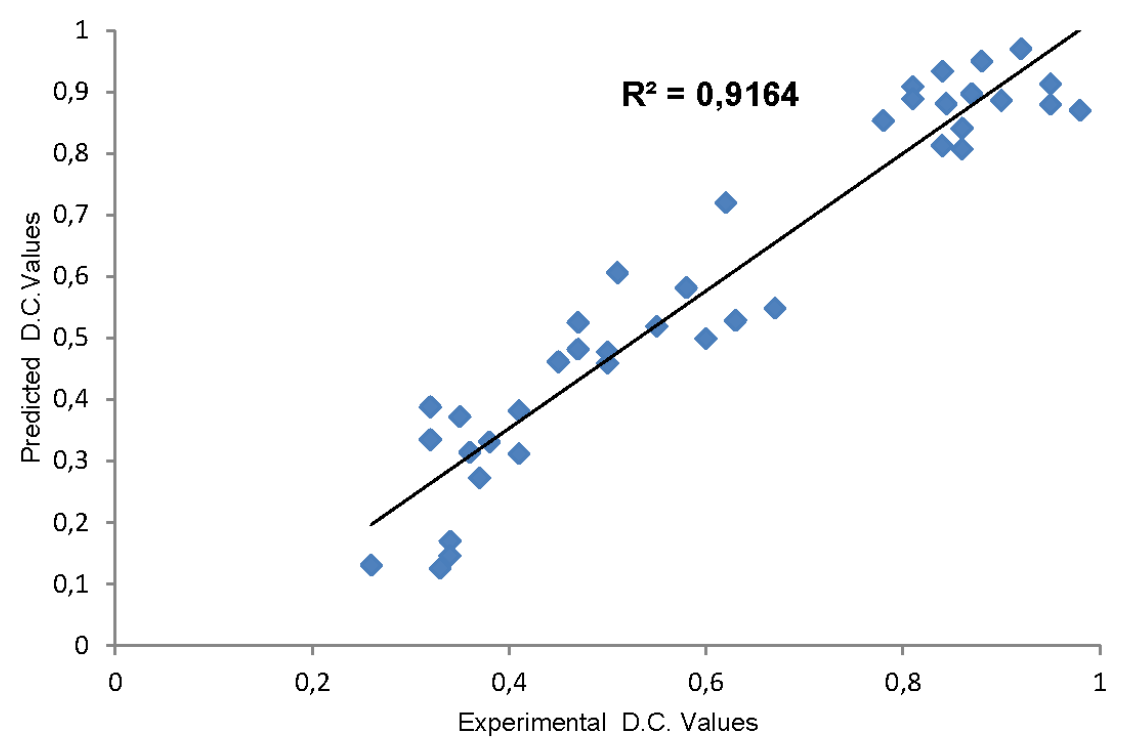

Figure 11. the relation between predicted and measured DC 


\section{References}

[1] Abbott, G.M., Grosberg, P., \& Leaf. (1973). The Elastic Resistance to Bending of Plain-Woven Fabrics. Journal of the Textile Institute, 64 6, 346-362.

[2] Antony, L., Amar, K., \& Muthu, G. (2004). Neural Network Models for Fabric Drape Prediction. IEEE, 2925-2929.

[3] Behre, B. (1961). Mechanical Properties of Textile Fabrics, Part I: Shearing. Textile Research Journal, 31 2, 87-99.

[4] Chattopadhyay, R., \& Guha, A., (2004). Artificial Neural Networks: Applications to Textiles. The Textile Institute, textile progress, 35 1, 301-317.

[5] Chu, C.C., Cummings, C.L., \& Texeira, N.A. (1950). Mechanics of Elastic Performance of Textile Materials PartV: A Study of the Factors Affecting the Drape of Fabrics-The Development of a Drape Meter. Journal of textile institute, 20 8, 539-548.

[6] Chu, C.C., Platt, M.M., \& Hamburger, W.J. (1960). Investigation of the Factors Affecting the Drapeability of Fabrics. Textile Research Journal, 30 1, 66-67.

[7] Collier, J. R., Billie, J. C., Gina, O., \& Sargand. M. (1991). Drape Prediction by Means of Finite-element Analysis. Journal of the Textile Institute, 82 1, 96-107.

[8] Cooper, D.N.E. (1960), The Stiffness of Woven Textiles. Journal of Textile Institute, 51 8, T317-T335.

[9] Cusick, G.E. (1965). The dependence of Fabric Drape on Bending and Shearing Stiffness, Journal of the Textile Institute, 65 5, 596-606.

[10] Cusick, G. E. (1968). The Measurement of Fabric Drape. Textile Research Journal, 59 6, 253-260.

[11] Dahlberg, B. (1961). Mechanical Properties of Textile Fabrics Part II: Buckling. Textile Research Journal, 312 , 87-99.

[12] Frédéric, D. (1997). Image Filtering Using Neural Networks, MIME Department, University of Paris 8, Septembre. Retrieved from www.mime.univ-paris8.fr
[13] George, K. S., \& Ren, Z., (1997). The Characterization of the Static and Dynamic Drape of Fabrics. Journal of the Textile Institute, 88 4, 465-475.

[14] Grosberg, P. (1966). The Mechanical Properties of Woven Fabrics, Part II: The Bending of Woven Fabrics. Textile Research Journal, 36 3, 250-211.

[15] Hamdi, T., Ghith, A., \& Fayala, F. (2014). A Principal Component Analysis (PCA) Method For Predicting the correlation Between Some Fabrics Parameter and the Drape. Autex research Journal, 14 1, 22-27.

[16] Hu, J. L., \& Chan, Y. F. (1998). Effect of Fabric Mechanical Properties on Drape. Textile Research Journal, 68 1, 5764.

[17] Jedda H., Ghith A. \& Sakli F. (2007). Prediction of Fabric Drape Using FAST System. Journal of the Textile Institute 98 3, 219-225.

[18] Jeong, Y. J., \& Philips, P. G. (1991). A Study of Fabric Drape Behavior with Image Analysis, Part II: The Effect of Fabric Structure and Mechanical Properties on Fabric Drape, Journal of the Textile Institute 89, Part1, 1, 70-79.

[19] Lindberg, J., Behre. B., \& Dahlberg. B., (1961), Mechanical Properties of Textile Fabrics, Part III Shearing and Buckling of Various Commercial Fabrics. Textile Research Journal, 31 2, 99-122.

[20] Luger. G.F., \& Stubblefield. W.A. 1993. Artificial Intelligence: Structures and Strategies for Complex Problem Solving. 2nd Edition, Benjamin/Cumming Publishing, Redwood City, California.

[21] McClelland, J.L., Rumelhart, D.E., \& Hinton, G.E. (1986). The Appeal of Parallel Distributed Processing, in Parallel Distributed Processing: Explorations in the Microstructure of Cognition - Foundations, 1, MIT Press, Cambridge, 3-44.

[22] Oloffson B. (1964). A General Model of Fabric as Geometric-Mechanical Structure. Journal of the Textile Institute 55 11, 541-557.

[23] Pierce, F.T. (1930). The Handle Cloth as a Measurable Quantity. Journal of the Textile Institute 21 6, 377-417. 